\title{
Successive Translocation into and out of the Mitochondrial Matrix: Targeting of Proteins to the Intermembrane Space by a Bipartite Signal Peptide
}

\author{
Franz-Ulrich Hartl," Joachim Ostermann," \\ Bernard Guiard, $\dagger$ and Walter Neupert* \\ * Institut für Physiologische Chemie \\ Goethestrasse 33 \\ 8000 München 2, Federal Republic of Germany \\ tCentre de Genetique Moleculaire \\ 91190 Gif-sur-Yvette, France
}

\section{Summary}

We investigated the import and sorting pathways of cytochrome $b_{2}$ and cytochrome $c_{1}$, which are functionally located in the intermembrane space of mitochondria. Both proteins are synthesized on cytoplasmic ribosomes as larger precursors and are processed in mitochondria in two steps upon import. The precursors are first translocated across both mitochondrial membranes via contact sites into the matrix. Processing by the matrix peptidase leads to intermediatesized forms, which are subsequently redirected across the inner membrane. The second proteolytic processing occurs in the intermembrane space. We conclude that the hydrophobic stretches in the presequences of the intermediate-sized forms do not stop transfer across the inner membrane, but rather act as transport signals to direct export from the matrix into the intermembrane space.

\section{Introduction}

Transport of proteins into mitochondria can be subdivided into several distinct steps (for reviews see Hay et al., 1984; Harmey and Neupert, 1985; Pfanner and Neupert, 1987): Nuclear-coded mitochondrial proteins are synthesized on free polysomes as precursors, most of which have aminoterminal peptide extensions, and are released into cytosolic pools (Hallermayer et al., 1977; Schatz, 1979). Precursors are located to mitochondria via targeting signals contained either in the presequences or in some cases in the mature parts of the precursors (Hurt et al., 1984a; 1984b; Horwich et al., 1985; Pfanner et al., 1987b). They bind to specific receptors on the surface of mitochondria (Zwizinski et al., 1984). Insertion into and translocation across the inner mitochondrial membrane are dependent on the mitochondrial membrane potential (Schleyer et al., 1982; Gasser et al., 1982a; Kolanski et al., 1982; Pfanner and Neupert, 1985) and in addition requires nucleoside triphosphates (Pfanner and Neupert, 1986; Pfanner et al., 1987c; Chen and Douglas, 1987; Eilers et al., 1987; Hartl et al., 1987a); translocation occurs at contact sites between outer and inner membranes (Schleyer and Neupert, 1985; Hartl et al., 1986; Schwaiger et al., 1987; Hartl et al., 1987a; Pfanner et al., 1987a). Precursors are proteolytically processed by the metal-dependent processing peptidase located in the mitochondrial matrix (Böhni et al., 1980; Miura et al., 1982; Conboy et al., 1982;
McAda and Douglas, 1982; Schmidt et al., 1984). Finally, most of the imported proteins are assembled into supramolecular complexes (Lewin and Norman, 1983; Schmidt et al., 1983; Dowhan et al., 1985; Hartl et al., 1986).

This overall sequence of events, however, does not describe the individual reactions responsible for the intramitochondrial sorting of precursor proteins to the different submitochondrial compartments. Proteins of the intermembrane space or of the outer surface of the inner membrane reaching into the intermembrane space seem to follow the most complex sorting and assembly pathways. Two-step proteolytic processing has been found to be a common feature for some of these proteins including cytochrome b (Daum et al., 1982; Gasser et al., 1982b), cytochrome c peroxidase (Kaput et al., 1982), cytochrome $c_{1}$ (Gasser et al., 1982b; Ohashi et al., 1982; Teintze et al., 1982), and the Rieske Fe/S protein of complex III (Hartl et al., 1986). In each case the first proteolytic processing step is performed by the matrix peptidase; that is, precursors have to be translocated either completely or at least partially across the inner membrane.

In the present report we describe distinct steps in the import and sorting pathways of cytochromes $b_{2}$ and $c_{1}$. Cytochrome $b_{2}$ is a soluble component of the intermem. brane space of yeast mitochondria (Daum et al., 1982). Cytochrome $c_{1}$ is anchored to the inner membrane but reaches into the intermembrane space with a large hydrophilic portion (Li et al., 1981). Both precursors are imported via translocation contact sites (Schleyer and Neupert, 1985; Hartl et al., 1987a; Pfanner et al., 1987a). They are made with large presequences of 80 amino acids in the case of cytochrome $b_{2}$ (Guiard, 1985) and of 61 and 70 residues in case of yeast and Neurospora cytochrome $c_{1}$, respectively (Sadler et al., 1984; Römisch et al., 1987). These prepieces have two distinguishable domains. Their amino-terminal parts exhibit the features of typical matrix targeting signals (Hurt and van Loon, 1986), while their carboxy-terminal parts contain a hydrophobic stretch of approximately 20 amino acid residues. This region has been suggested to function as a "stop-transfer" sequence prohibiting complete translocation of the precursor across the inner mitochondrial membrane (Guiard, 1985; van Loon et al., 1986; van Loon and Schatz, 1987; van Loon et al., 1987). A similar mechanism has been proposed for the precursor to cytochrome $c$ peroxidase (Kaput et al., 1982).

The experiments presented here suggest that the precursors of cytochromes $b_{2}$ and $c_{1}$ are first translocated across both membranes into the matrix of mitochondria in a membrane potential-dependent reaction. Following cleavage by the processing peptidase, the resulting intermediate-sized species are directed across the inner membrane in the opposite direction. The second processing, which takes place at the outer surface of the inner membrane, leads to the formation of the mature proteins.

We conclude that the hydrophobic segments in the carboxy-terminal parts of the presequences do not stop 


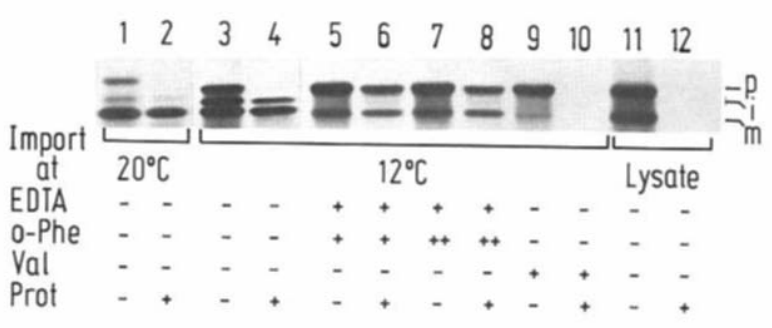

Figure 1. Import of Cytochrome $b_{2}$ into Isolated Mitochondria

A postribosomal supernatant of a reticulocyte lysate containing radio labeled $p-b_{2}$ was supplemented with unlabeled methionine and sucrose and diluted 1:5 with BSA buffer (see Experimental Procedures). It was divided into $200 \mu \mathrm{l}$ aliquots, and each was made $2 \mathrm{mM} \mathrm{NADH}$ and $1.5 \mathrm{mM}$ ATP (added from a $100 \mathrm{mM}$ stock solution in water, neutralized to $\mathrm{pH} 7.0$ with $1 \mathrm{~N} \mathrm{KOH}$ prior to use). Where indicated, reactions were brought to $10 \mathrm{mM}$ EDTA, $1 \mathrm{mM}(+)$, and $2 \mathrm{mM}(++)$ o-phenanthroline (o-Phe), respectively, or to $1 \mu \mathrm{M}$ valinomycin (Val). To each reaction, mitochondria were added to a final concentration of 0.5 $\mathrm{mg} / \mathrm{ml}$, and incubation was for $30 \mathrm{~min}$ at $20^{\circ} \mathrm{C}$ (lanes 1 and 2) or $12^{\circ} \mathrm{C}$ (lanes 3-10). Afterward mitochondria were reisolated and resuspended in $200 \mu$ l of SEOM buffer $(0.25 \mathrm{M}$ sucrose, $5 \mathrm{mM}$ EDTA, $1 \mathrm{mM}$ o-phenanthroline, and $10 \mathrm{mM}$ MOPS [pH 7.2]) and divided into two portions. One portion was left on ice for 30 min (lanes 1, 3, 5, 7, and 9); the other was treated with proteinase $\mathrm{K}$ (Prot) at $15 \mu \mathrm{g} / \mathrm{ml}$, final concentration (lanes $2,4,6,8$, and 10). Then all reactions received PMSF to $1 \mathrm{mM}$, and mitochondria were reisolated. The mitochondrial pellets were washed once with SEOM buffer and finally dissociated in SDScontaining sample buffer for electrophoresis. As a control, one aliquot of reticulocyte lysate was diluted 1:5 with SEOM and divided into halves, one of which was treated with proteinase $\mathrm{K}$. Both reactions were precipitated with TCA. Of the amount of lysate used in the import reactions, $50 \%$ was applied in lanes 11 and 12 . A fluorograph of the dried gel is shown. The positions of $p-b_{2}(p), i-b_{2}(i)$, and $m-b_{2}(m)$ are indicated.

transport of the precursors across the inner mitochondrial membrane, but function as signals to direct the reverse translocation of the intermediate-sized forms from the mitochondrial matrix across the inner membrane. We suggest that the mechanism of this export from the mitochondrial matrix shares a common origin with the mechanism of protein export from the cytoplasm into the periplasmic space in prokaryotes.

\section{Results}

\section{Upon Inhibition of the Processing Peptidase, Precursor to Cytochrome $b_{2}$ Is Imported into a Protease-Protected Position by Isolated Yeast Mitochondria}

Precursor to cytochrome $b_{2}\left(p-b_{2}\right)$ was synthesized from the cloned DNA by coupled transcription-translation in rabbit reticulocyte lysate in the presence of $\left[{ }^{35}\right.$ S]methionine. For import of the precursor, reticulocyte lysate and isolated mitochondria were combined and incubated at different temperatures. At $20^{\circ} \mathrm{C}$, precursor was imported into mitochondria and processed to mature-sized cytochrome $b_{2}\left(m-b_{2}\right)$ (Figure 1, lane 1$)$; this $m-b_{2}$ was in a position protected from externally added proteinase K (Figure 1, lane 2). Under these conditions, only small amounts of precursor were present on the surface of mitochondria. When import was performed at $12^{\circ} \mathrm{C}$, in addition to $m-b_{2}$, considerable amounts of precursor and intermediatesized $b_{2}\left(i-b_{2}\right)$ accumulated (Figure 1, lanes 3 and 4). Precursor was digested by protease, whereas $50 \%-60 \%$ of $i-b_{2}$ and some $90 \%$ of $m-b_{2}$ were protected. We have recently shown that at lower temperatures $\left(7^{\circ} \mathrm{C}-12^{\circ} \mathrm{C}\right) \mathrm{i}-\mathrm{b}_{2}$ spanning both outer and inner membranes at translocation contact sites accumulated (Pfanner et al., 1987a). Protease-sensitive $\mathrm{i}-\mathrm{b}_{2}$ formed at $12^{\circ} \mathrm{C}$ represented such a contact site intermediate.

When the chelators EDTA and o-phenathroline were added in combination to the import reaction at $12^{\circ} \mathrm{C}$ to inhibit the processing peptidase in the matrix (Schmidt et al., 1984), formation of $m-b_{2}$ was decreased and large amounts of the precursor were associated with mitochondria (Figure 1, lanes 5-8). Most of this precursor was resistant to added protease; thus, it was at least translocated across the outer membrane. In contrast to results with the Rieske $\mathrm{Fe} / \mathrm{S}$ protein in Neurospora mitochondria (Hartl et al., 1986), processing of $p-b_{2}$ in yeast mitochondria could be inhibited only partially. The amount of $\mathrm{i}-\mathrm{b}_{2}$ relative to $m-b_{2}$ is decreased because formation of $i-b_{2}$ is much slowed by the presence of metal chelators, whereas its conversion to $m-b_{2}$ is not affected.

Import of cytochrome $b_{2}$ was dependent on the membrane potential across the inner mitochondrial membrane. When the membrane potential was dissipated by adding the potassium ionophore valinomycin (in the presence of $80 \mathrm{mM} \mathrm{KCl}$ outside), precursor and small amounts of "pseudomature" $b_{2}$ were associated with the surface of mitochondria; both were completely degraded by added proteinase K (Figure 1, lanes 9 and 10). The same sensitivity to added protease was found for precursor and pseudomature $b_{2}$ in the reticulocyte lysate, indicating that adequate concentrations of protease were applied in the protection assays (Figure 1, lanes 11 and 12). Formation of pseudomature $b_{2}$ most likely resulted from internal initiation of translation at the methionine in position +6 of the mature sequence (Guiard, 1985).

\section{Imported Precursor of Cytochrome $b_{2}$ is Located in the Matrix of Mitochondria}

The various forms of imported cytochrome $b_{2}$ were analyzed for their extractability by $0.1 \mathrm{M}$ sodium carbonate (data not shown) (for method see Pfanner et al., 1987a). $m-b_{2}$ was fully extractable, as was to be expected for a soluble intermembrane space protein. Also, precursor that was in a protease-protected position and both protease-sensitive and protease-protected $i-b_{2}$ were completely solubilized by treatment at alkaline $\mathrm{pH}$. Apparently $p-b_{2}$ and $i-b_{2}$ either were not membrane-integrated species or were present in the inner membrane in a hydrophilic environment accessible to aqueous perturbants.

To examine further the submitochondrial arrangement of the various forms of cytochrome $b_{2}$, we analyzed their solubility in buffers of increasing ionic strength (Figure 2). Imported $m-b_{2}$ and preexistent unlabeled $m-b_{2}$ (measured as lactate ferricyanide reductase) were largely soluble without addition of salt to the extraction buffer. A salt concentration of $0.2 \mathrm{M}$ was sufficient to extract $60 \%-70 \%$ of imported $\mathrm{p}-\mathrm{b}_{2}$ and about $40 \%$ of $\mathrm{i}-\mathrm{b}_{2}$. Higher salt con- 


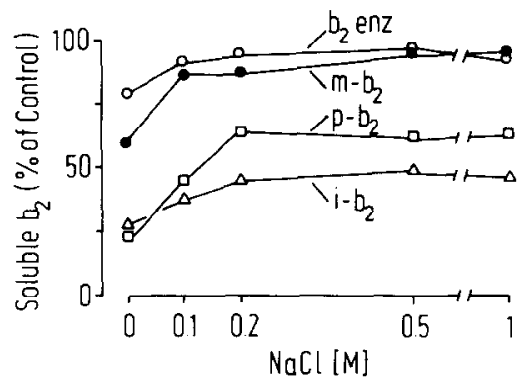

Figure 2. Extractability of the Various Forms of Cytochrome $b_{2}$ with Salt

Mitochondria were reisolated from import reactions and resuspended at a protein concentration of $0.1 \mathrm{mg} / \mathrm{ml}$ in SEOM buffer containing $0-1$ $\mathrm{M} \mathrm{NaCl}$. Samples were sonicated at $0^{\circ} \mathrm{C}-4^{\circ} \mathrm{C}$ (Branson sonifier with topend microtip; setting 3, pulsed, $40 \%$ duty, three 1 min pulses with two 1 min cooling intervals) and divided into two portions. One was kept on ice for determination of recoveries (total); the other was separated into pellets and supernatants by centrifugation for $1 \mathrm{hr}$ at $165,000 \times \mathrm{g}$. Pellets were resuspended in buffer containing the respective salt concentration and brought to the same volume as supernatants. Aliquots corresponding to $25 \mu \mathrm{g}$ of untreated mitochondria were taken for determination of cytochrome $b_{2}$ enzyme activity. All samples were made $0.0125 \%$ in deoxycholate, and after $5 \mathrm{~min}$ on ice, TCA was added to a final concentration of $10 \%$. Incubation on ice was continued for 30 $\mathrm{min}$, and precipitates were collected by centrifugation ( $15 \mathrm{~min}, 48,000$ $x \mathrm{~g})$. They were washed once in acetone and finally dissociated in SDS-containing buffer. Fluorographs of dried gels were analyzed by densitometry. Data are expressed as the percentages of total cytochrome $b_{2}$ recovered in the supernatants. Recoveries of total cytochrome $b_{2}$ in supernatants and pellets varied between $85 \%$ and $98 \%$. Open circles indicate enzyme activity of preexisting $b_{2}\left(b_{2}\right.$ enz); closed circles, $m-b_{2}$ imported at $20^{\circ} \mathrm{C}$; open squares, protease-protected $p-b_{2}$ accumulated at $12^{\circ} \mathrm{C}$ in the presence of EDTA and o-phenanthroline open triangles, protease-protected $i-b_{2}$ accumulated at $12^{\circ} \mathrm{C}$. Experimental conditions for import as in Figure 1.

centrations did not lead to further release of these species into the soluble fraction.

Most of imported $p-b_{2}$ and approximately half of $i-b_{2}$ were water-soluble and were therefore not integrated into the inner membrane. Approximately $30 \%$ of $p-b_{2}$ and $50 \%$ of $\mathrm{i}-\mathrm{b}_{2}$, however, behaved differently in that they were tightly associated with the inner membrane.

Soluble precursor and intermediate could thus be located in either the intermembrane space or the matrix of mitochondria. To decide which is the correct location, mitochondria that had imported precursor in the presence of chelators and mitochondria that had imported precursor in the absence of chelators were mixed (see Figure 1), incubated with proteinase $K$ to digest material accessible to external protease, and treated with increasing concentrations of digitonin in the presence of $0.2 \mathrm{M}$ salt. The contents of intermembrane space (marker lactate-ferricyanide reductase) and matrix (marker fumarase) were successively released (Figure $3 A$ ). Imported $m-b_{2}$ cofractionated exactly with preexisting cytochrome $b_{2}$ and was released at low concentrations of digitonin between $0.025 \%$ and $0.075 \%$, while fumarase was still found in the pellet fractions (Figure $3 \mathrm{~B}$ ). Imported precursor and intermediate soluble at $0.2 \mathrm{M}$ salt (see Figure 2) were released from mitochondria in parallel with fumarase. It therefore appears
A

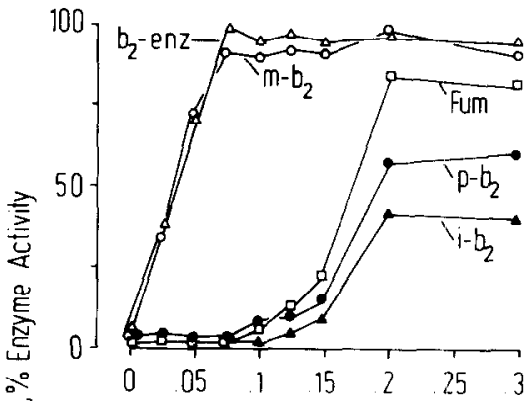

$B$

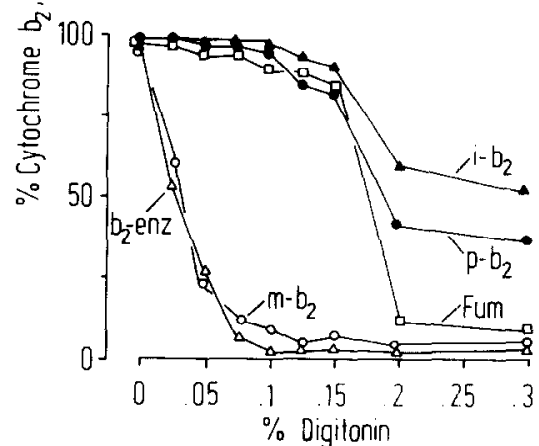

Figure 3. Release of Imported $p-b_{2}$ and $i-b_{2}$ from Mitochondria by Treatment with Digitonin

In one reaction import was performed at $12^{\circ} \mathrm{C}$ to accumulate $\mathrm{i}-\mathrm{b}_{2}$ and $m-b_{2}$. In another import reaction EDTA and o-phenanthroline were added to accumulate $p-b_{2}$ (for experimental details see Figure 1). Mitochondria were reisolated and resuspended in SEOM buffer. Both reactions were combined. After treatment with proteinase $K$, mitochondria were again reisolated and resuspended at a protein concentration of $10 \mathrm{mg} / \mathrm{ml}$ in SEOMK buffer (SEOM buffer containing $200 \mathrm{mM} \mathrm{KCl}$, $0.1 \mathrm{mM}$ PMSF, and $0.5 \mathrm{mg} / \mathrm{ml}$ protease inhibitor from N. crassa). The reaction was divided into nine aliquots. Digitonin was added to concentrations of $0 \%-0.3 \%$, and incubation was for $1 \mathrm{~min}$ at $0^{\circ} \mathrm{C}$ in a final volume of $30 \mu \mathrm{l}$ and at a protein concentration of $5 \mathrm{mg} / \mathrm{ml}$. Afterward reactions were diluted 5-fold with SEOMK and separated into pellets and supernatants. Pellets were resuspended in SEOMK to the same volume as the supernatants. Aliquots corresponding to $50 \mu \mathrm{g}$ of untreated mitochondria were precipitated with TCA. The remaining parts of the samples were brought to $1 \%$ Genapol (Hoechst) and used for determination of marker enzymes. TCA precipitates were separated by electrophoresis, and fluorographs were evaluated by densitometry. Enzyme activities and amounts of cytochrome $b_{2}$ in supernatants (A) and pellets $(B)$ are expressed as percentages of the total activities. $b_{2}$-enz, enzymatic $b_{2}$ measured as lactate ferricyanide reductase activity; Fum, fumarase.

that two-thirds of imported $p-b_{2}$ and about one-half of $i-b_{2}$ are soluble proteins located in the matrix of mitochondria.

This result was further substantiated when mitochondria containing accumulated precursor or intermediate were fractionated by osmotic shock treatment (Daum et al., 1982; van Loon et al., 1986). Most of the soluble intermembrane space content (preexisting cytochrome $b_{2}$ ) was released after incubation in 0-0.1 $\mathrm{M}$ sorbitol, whereas only $10 \%-15 \%$ of fumarase was set free (data not shown). After osmotic shock, the different incubations were brought to isoosmolarity and treated with proteinase $K$. Preexisting $b_{2}$ and imported $m-b_{2}$ were completely digested in shocked mitochondria (Figure 4A, lanes 3 and 4); however, more than $60 \%$ of the precursor was still resistant to externally added protease. In contrast, only 


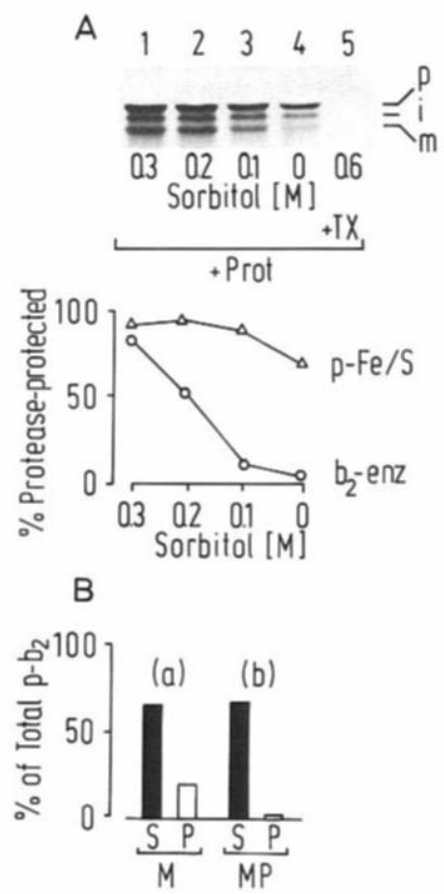

Figure 4. Submitochondrial Localization of Imported $b_{2}$ by Osmotic Shock Treatment of Mitochondria

(A) Accessibility to protease of the various forms of $b_{2}$ in mitoplasts. Mitochondria that had accumulated $p-b_{2}$ and $p-F e / S$ and mitochondria that had accumulated $i-b_{2}$ and $m-b_{2}$ were combined (for experimental details see Figure 3). They were divided into five aliquots of $200 \mu \mathrm{g}$ each and incubated for $15 \mathrm{~min}$ at $0^{\circ} \mathrm{C}$ in MOPS buffer containing $5 \mathrm{mM}$ EDTA, $1 \mathrm{mM}$ o-phenanthroline, and 0-0.3 $\mathrm{M}$ sorbitol (final concentrations) (see Experimental Procedures). Then the reactions were adjusted to $0.6 \mathrm{M}$ sorbitol. Half of each reaction was separated into pellets and supernatants and used for the determination of lactate ferricyanide reductase and fumarase (data not shown). The other halves were treated with proteinase $\mathrm{K}$ (+Prot) and aliquots were used for enzyme determination (lower panel). The residual parts of the samples were TCA-precipitated and analyzed by electrophoresis and fluorography (lanes 1-5). The reaction shown in lane 5 was made 1\% Triton X-100 $(+\mathrm{TX})$ prior to treatment with proteinase $\mathrm{K}$. The amount of proteaseprotected $\mathrm{p}-\mathrm{F} \theta / \mathrm{S}$ was quantified by densitometry (lower panel). Data are expressed as percentages of total p-Fe/S and enzyme activities, respectively, protease-protected in controls $(0.3 \mathrm{M}$ sorbitol). The positions of $p-b_{2}(p), i-b_{2}(i)$, and $m-b_{2}(m)$ are indicated.

(B) Extractability by salt of $p-b_{2}$ accumulated in mitoplasts. Mitochondria that had accumulated $\mathrm{p}-\mathrm{b}_{2}$ were incubated in $0.3 \mathrm{M}$ sorbitol (a) or $0.05 \mathrm{M}$ sorbitol (b) (experimental conditions as in [A]). After protease treatment, mitochondria and mitoplasts, respectively, were reisolated and subjected to salt extraction in SEOM buffer containing $200 \mathrm{mM}$ $\mathrm{NaCl}$ (experimental conditions as in Figure 2). After electrophoresis and fluorography, $p-b_{2}$ in pellets $(P)$ and supernatants $(S)$ was quantified by densitometry. Data are expressed as percentages of total $p-b_{2}$ protease-protected in intact mitochondria. $M$, mitochondria $(0.3 \mathrm{M}$ sorbitol); MP, mitoplasts (0.05 M sorbitol).

$30 \%-40 \%$ of $\mathrm{i}-\mathrm{b}_{2}$ remained protease-protected in osmotically shocked mitochondria. As a sensitive indicator for protease access to the matrix, precursor of Rieske $\mathrm{Fe} / \mathrm{S}$ protein was accumulated in the matrix in addition to cytochrome $b_{2}$ (Hartl et al., 1986; van Loon and Schatz, 1987). This p-Fe/S was protease-protected in mitochondria with ruptured outer membrane to about the same extent as was $p-b_{2}$. The protease protection of $p-b_{2}, i-b_{2}$,

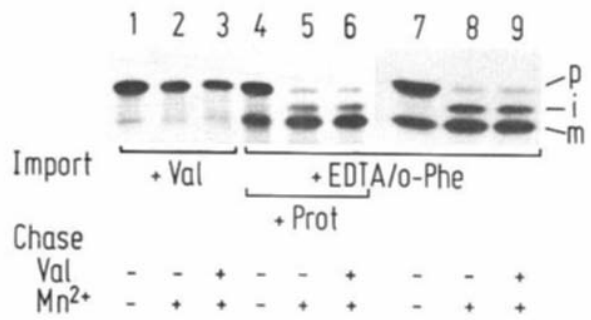

Figure 5. Processing of Imported $p-b_{2}$ to $m-b_{2}$

Mitochondria were incubated in reticulocyle lysates containing radiola beled $p-b_{2}$ for $30 \mathrm{~min}$ at $12^{\circ} \mathrm{C}$ (experimental conditions of import as in Figure 1). The first group of reactions (lanes 1-3) contained valinomycin (+Val) to block the membrane potential across the inner membrane. To the second and third groups of reactions (lanes 4-6 and lanes 7-9) EDTA and o-phenanthroline (+EDTA/o-Phe) was added to inhibit the processing peptidase in the matrix. After import mitochondria were reisolated and resuspended in sucrose/MOPS buffer containing $0.5 \mathrm{mM}$ EDTA and $0.5 \mathrm{mM}$ o-phenanthroline to maintain the block of the peptidase. The second group of reactions (lanes 4-6) was treated with proteinase $K$ (+Prot) to remove $p-b_{2}$ either bound to the surface of mitochondria or accumulated in contact sites. Prior to a chase period for $15 \mathrm{~min}$ at $20^{\circ} \mathrm{C}$, valinomycin and $\mathrm{MnCl}_{2}(1 \mu \mathrm{M}$ and 1.5 $\mathrm{mM}$, final concentrations, respectively) were added when indicated. Subsequently, mitochondria were reisolated and analyzed by electrophoresis and fluorography. The positions of $p-b_{2}(p), i-b_{2}(i)$, and $m-b_{2}(m)$ are indicated.

and $\mathrm{p}-\mathrm{Fe} / \mathrm{S}$ in mitoplasts was completely abolished after mild sonication or addition of Triton $\mathrm{X}-100$.

$p-b_{2}$ protected against protease in mitoplasts was tested for its solubility (Figure 4B, columns b). This fraction of the precursor was found to be completely soluble at a salt concentration as low as $0.2 \mathrm{M} \mathrm{NaCl}$, in contrast to total imported precursor (see above; Figure 4B, columns a).

These data show that $p-b_{2}$ was translocated across both mitochondrial membranes and was present as a water-soluble species in the matrix. A fraction of total imported precursor (approximately $35 \%$ ) was tightly membrane- associated and was located on the outer surface of the inner membrane in mitoplasts. Likewise, about $60 \%$ of $\mathrm{i}-\mathrm{b}_{2}$ accumulated at $12^{\circ} \mathrm{C}$ was exposed to the outer face of the inner membrane, the other $40 \%$ being soluble in the matrix.

\section{Precursor and Intermedlate-Sized Form of Cytochrome $b_{2}$ Accumulated in the Matrix Are on the Correct Import Pathway}

Precursor was imported into mitochondria at $12^{\circ} \mathrm{C}$ in the presence of EDTA and o-phenanthroline, i.e., under conditions where the matrix peptidase was partially inhibited (Figure 5, lanes 4-9). Half of the sample was treated with proteinase $\mathrm{K}$ to remove precursor bound to the surface of mitochondria (Figure 5, lanes 4-6). Mitochondria were then reisolated and resuspended in fresh sucrose/MOPS buffer to which different additions were made. When EDTA and o-phenanthroline were added as during import, the block of the matrix peptidase was maintained (Figure 5, lanes 4 and 7). When $\mathrm{Mn}^{2+}$ ions were added and the reactions were warmed up to $20^{\circ} \mathrm{C}$, most of $p-b_{2}$ became processed to $m-b_{2}$ (Figure 5 , lanes $5,6,8$, and 9 ). Also, in the case in which treatment with protease after import had 

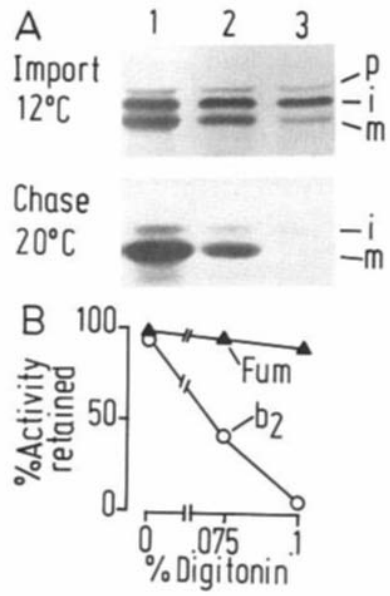

Figure 6. Transport of $i-b_{2}$ from the Matrix across the Inner Membrane

Mitochondria that had accumulated $\mathrm{i}-\mathrm{b}_{2}$ and $\mathrm{m}-\mathrm{b}_{2}$ at $12^{\circ} \mathrm{C}$ (for experimental details see Figure 1) were reisolated and resuspended in sucrose/MOPS buffer containing $80 \mathrm{mM} \mathrm{KCl}$ and $1 \mu \mathrm{M}$ valinomycin. The sample was halved. The first half was kept on ice, while the second was incubated for $15 \mathrm{~min}$ at $20^{\circ} \mathrm{C}$ (Chase). Mitochondria were reisolated from both samples, and digitonin fractionation was performed (experimental details as in Figure 3). Concentrations of digitonin ap plied were $0 \%, 0.075 \%$, and $0.1 \%$ (corresponding to lanes 1-3).

(A) Reactions were treated with proteinase K, TCA-precipitated, and analyzed by electrophoresis and fluorography. The positions of $p-b_{2}$ (p), $i-b_{2}(i)$, and $m-b_{2}(m)$ are indicated.

(B) Aliquots were taken prior to protease treatment and separated into pellets and supernatants. Marker enzymes lactate ferricyanide reductase $\left(b_{2}\right)$ and fumarase (Fum) were determined. Data are expressed as enzyme activities retained in pellets. Results were not influenced by whether reactions were submitted to the chase at $20^{\circ} \mathrm{C}$ or were kept on ice. Therefore only one set of data is shown.

been omitted, very little precursor remained unprocessed. Most likely part of this precursor, which had not yet been in a protease-protected position (Figure 5, lane 4 and 7; see Figure 1), was spanning both outer and inner membranes at contact sites. In agreement with this, $p-b_{2}$ was chased to $m-b_{2}$ with the same efficiency when the membrane potential across the inner membrane had been dissipated by valinomycin (plus potassium) (Figure 5, lanes 6 and 9). Thus precursor located in contact sites was already past the membrane potential-dependent step of the import pathway. As a control for the effective inhibition of import, valinomycin was included during the import reaction (Figure 5 , lanes $1-3$ ). In this case no processing of $p-b_{2}$-was observed during a subsequent chase period

To substantiate further the view that matrix-localized $p-b_{2}$ and $i-b_{2}$ are on the native import and sorting pathway, a second type of experiment was performed. Import was carried out at $12^{\circ} \mathrm{C}$, resulting in the formation of both $i-b_{2}$ and $m-b_{2}$ (Figure 6). Mitochondria were reisolated and resuspended in fresh import buffer. Valinomycin was included to dissipate the membrane potential. One-half of the reaction was then incubated at $20^{\circ} \mathrm{C}$, while the other half was kept at $12^{\circ} \mathrm{C}$. Mitochondria were treated with low concentrations of digitonin to open the intermembrane space selectively. Then the resulting mitoplasts were treated with proteinase $\mathrm{K}$. With a concentration of $0.1 \%$ digitonin the outer membrane barrier was sufficiently disrupted to completely set free preexisting cytochrome $b_{2}$ (determined enzymatically), while most of fumarase activity was retained. Imported $m-b_{2}$ was digested (Figure 6 , lane 3). In agreement with the results shown in Figure 4, about $40 \%$ of $\mathrm{i}-\mathrm{b}_{2}$ imported at $12^{\circ} \mathrm{C}$ was protected against protease in mitoplasts (Figure 6, lane 3). During the chase period at $20^{\circ} \mathrm{C}$, most of this $\mathrm{i}-\mathrm{b}_{2}$ was processed to protease-sensitive $m-b_{2}$ (Figure 6 , lanes $1-3$ ). The small amount of $i-b_{2}$ that remained unprocessed also became accessible to protease.

From these data we conclude that $i-b_{2}$ accumulated in the matrix at low temperature became redirected across the inner membrane. At the outer surface of the inner membrane, processing of $i-b_{2}$ results in the formation of $m-b_{2}$, which is then soluble in the intermembrane space. It seems possible that $p-b_{2}$ can also be retranslocated from the matrix to the intermembrane space, although with lower efficiency than $i-b_{2}$. The fraction of imported $p-b_{2}$ that was resistant to extraction with salt and became protease-sensitive in mitoplasts probably had already reached the matrix and was retranslocated across the inner membrane (Figure 4B).

\section{Precursor of Cytochrome $c_{1}$ Is Imported into a Protease-Protected Position by Isolated Neurospora Mitochondria}

In contrast to the results stated above, it was proposed recently that the hydrophobic segment in the presequence of cytochrome $c_{1}$ stops transfer of the precursor across the inner membrane (van Loon et al., 1986). In particular, precursor of a fusion protein between the presequence of cytochrome $c_{1}$ and dihydrofolate reductase was never de. tected in a protease-protected position in mitoplasts upon import in vitro (van Loon and Schatz, 1987). To resolve the problem as to whether or not cytochromes $b_{2}$ and $c_{1}$ follow different pathways, we have investigated the import of cytochrome $c_{1}$ into Neurospora mitochondria.

Radioactively labeled precursor to cytochrome $c_{1}$ from Neurospora crassa was synthesized from the cloned cDNA by coupled transcription-translation and imported into isolated mitochondria. Appropriate experimental conditions were chosen to accumulate distinct intermediates on the import pathway (Figure 7). In the presence of the chelators EDTA and o-phenanthroline, unprocessed precursor $\left(p-c_{1}\right)$ was translocated into a position within mitochondria protected against added proteinase $\mathrm{K}$ (Figure 7 , lanes 1 and 2). As with import of cytochrome $b_{2}$, inhibition of the first processing step was more efficient when import was carried out at lower temperature (Figure 7, lane 1 versus lane $2,8^{\circ} \mathrm{C}$ versus $25^{\circ} \mathrm{C}$ ). The second proteolytic processing from intermediate-sized $c_{1}\left(i-c_{1}\right)$ to mature $c_{1}$ $\left(m-c_{1}\right)$ was strongly dependent on the presence of $\mathrm{NADH}$. When NADH was omitted from the import reaction, $i-c_{1}$ was accumulated, which was also in a protease-protected location (Figure 7, lane 3). Presence of NADH led to the formation of $\mathrm{m}-\mathrm{c}_{1}$ (Figure 7, lane 4). When formation of a mitochondrial membrane potential was inhibited by a combination of antimycin A and oligomycin, import was completely abolished (Figure 7, lane 5). 


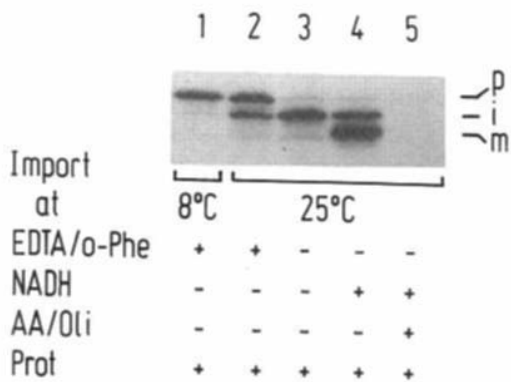

Figure 7. Import of Cytochrome $c_{1}$ into Isolated Mitochondria A postribosomal supernatant of a reticulocyte lysate containing radiolabeled $\mathrm{p}-\mathrm{c}_{1}$ was supplemented with unlabeled methionine and sucrose and diluted 1:10 with BSA buffer. Where indicated it was brought to $2 \mathrm{mM}$ NADH, $5 \mathrm{mM}$ EDTA, $0.1 \mathrm{mM}$ o-phenanthroline (EDTA/o-Phe), or $10 \mu \mathrm{M}$ and $40 \mu \mathrm{M}$ antimycin A and oligomycin (AA/Oli), respectively. To four $100 \mu$ laliquots, mitochondria of N. crassa were added to a concentration of $0.5 \mathrm{mg} / \mathrm{ml}$. Incubation was for $30 \mathrm{~min}$ at $25^{\circ} \mathrm{C}$. Then mitochondria were reisolated and resuspended in sucrose/MOPS buffer containing chelators as above. Treatment with proteinase K (Prot) (15 $\mu \mathrm{g} / \mathrm{ml}$, final concentration) was performed for $30 \mathrm{~min}$ on ice. Mitochondria were reisolated, dissociated in SDS-containing buffer, and analyzed by electrophoresis and fluorography. The positions of $p-c_{1}(p)$, $i-c_{1}(i)$, and $m-c_{1}(m)$ are indicated.

Translocation of the Precursor of Cytochrome $c_{1}$ across the Inner Membrane Is Not Prevented by the Hydrophobic Segment in the Presequence

$\mathrm{p}-\mathrm{c}_{1}$ and $\mathrm{p}$-Fe/S were imported into mitochondria at $8^{\circ} \mathrm{C}$ in the presence of EDTA and o-phenanthroline. After import, mitochondria were reisolated and treated with increasing concentrations of digitonin and a fixed concentration of proteinase K (Figure 8). Precursor to $c_{1}$ exhibited the same degree of protease resistance as $\mathrm{p}-\mathrm{Fe} / \mathrm{S}$. When the intermembrane space of mitochondria was opened by low concentrations of digitonin (as monitored by the release of adenylate kinase; data not shown), both precursors were still protected against added protease. They were only degraded when the digitonin concentration was raised to cause the release of the matrix marker fumarase (Figure 8, reaction 1; also see Figure 3). Specific fragments of $p-c_{1}$ due to partial digestion were not detectable.

If $p-c_{1}$ was first imported at $8^{\circ} \mathrm{C}$ as described above and the incubation mixture was then warmed to $25^{\circ} \mathrm{C}$ for $15 \mathrm{~min}$ in the presence of $\mathrm{Mn}^{2+}$ to reactivate the processing peptidase, $i-c_{1}$ was formed. When a membrane potential was established during the chase, this $i-c_{1}$ was digested by added protease once the outer membrane barrier had been disrupted by low concentrations of digitonin (Figure 8, reaction 2). However, i- $c_{1}$ was still largely protected against added protease in mitoplasts if prior to reactivation of the processing peptidase the membrane potential across the inner membrane had been abolished by a combination of antimycin $\mathrm{A}$ and oligomycin (Figure 8, reaction 3).

We interpret these results to indicate that $p-c_{1}$ was first translocated across both mitochondrial membranes. After the first processing step, $i-c_{1}$ was translocated in the reverse direction across the inner membrane to where the major part of the protein was exposed to the intermem-

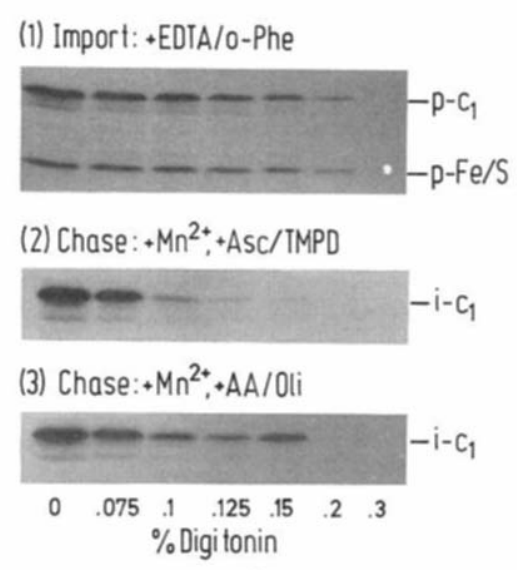

Figure 8. Submitochondrial Localization of Imported $p-c_{1}$ and $i-c_{1}$ $p-c_{1}$ and $p-F e / S$ were imported at $8^{\circ} \mathrm{C}$ in the presence of EDTA and o-phenanthroline (experimental conditions as in Figure 7). The sample was divided into three reactions. Mitochondria were reisolated and resuspended in BSA buffer. Reaction (1) was made $5 \mathrm{mM}$ EDTA and $0.1 \mathrm{mM}$ o-phenanthroline to maintain the block of the peptidase. Reaction (2) received $8 \mathrm{mM}$ ascorbate (added from a 10-fold concentrated stock solution, neutralized to $\mathrm{pH} 7.0$ with $\mathrm{KOH}$ ) and $0.2 \mathrm{mM}$ TMPD. Reaction (3) was made $10 \mu \mathrm{M}$ antimycin $\mathrm{A}$ and $40 \mu \mathrm{M}$ oligomycin. Then reactions (2) and (3) were brought to $1 \mathrm{mM} \mathrm{MnCl}_{2}$ to release the block of the peptidase and incubated for $15 \mathrm{~min}$ at $25^{\circ} \mathrm{C}$ (Chase). Reaction (1) remained on ice. Mitochondria were again reisolated from all three reactions and subjected to fractionation with digitonin (experimontal conditions as in Figures 3 and 6). Afterward each fraction was divided into halves. One half was seperated into pellets and supernatants for determination of marker enzymes (data not shown); the other was treated with proteinase $\mathrm{K}(15 \mu \mathrm{g} / \mathrm{ml}$, final concentration). Mitochondria were reisolated and analyzed by electrophoresis and fluorography.

brane space. Export of $i-c_{1}$ from the matrix across the inner membrane apparently was dependent on an energized inner membrane. So far it is unknown whether this behavior, which differs from the retranslocation of $i-b_{2}$, is due to differences between the mitochondria of the two species or is specific for cytochrome $c_{1}$.

The possibility that the differential protease digestibility of $p-c_{1}$ and $i-c_{1}$ could be an artifact due to a higher endogenous protease resistance of $p-c_{1}$ was carefully controlled for. After addition of $1 \%$ Triton X-100 to the protection assay, both species were completely degraded by the amount of protease routinely used (data not shown). We also titrated the protease resistance of imported $p-c_{1}$ and $\mathrm{i}-\mathrm{c}_{1}$ after disruption of the mitochondrial membranes by mild sonication (Figure 9). Already very low concentrations of proteinase $K(5 \mu \mathrm{g} / \mathrm{ml})$ were sufficient to digest $70 \%$ of imported $p-c_{1}$ and $i-c_{1}$ (Figure 9A). The residual part remained protease-protected also at higher concentrations of proteinase $\mathrm{K}$. It was, however, completely digested when protease was present during sonication (Figure 9B). Sonication is known to result in the formation of inner membrane vesicles of both orientations.

Due to technical reasons, we were unable to decide whether $p-c_{1}$ was also accumulated in the matrix as a soluble species. Less than $10 \%$ of imported $p-c_{1}$ was extractable in the presence of high salt concentrations $(0.5$ 


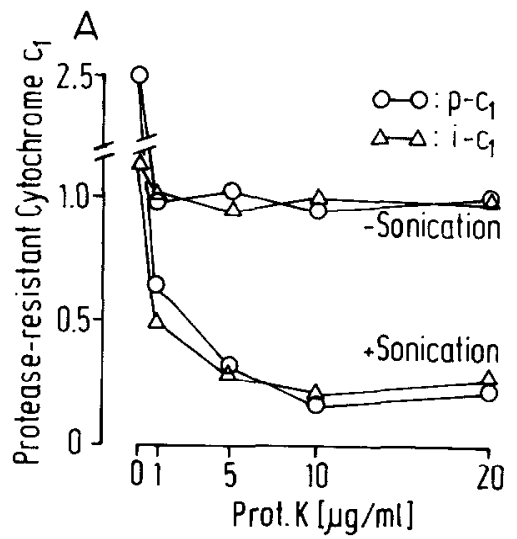

$\mathrm{B}$

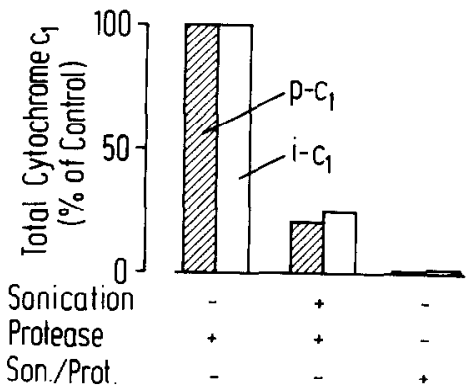

Figure 9. Titration of Endogenous Protease Resistance of $p-c_{1}$ and $\mathrm{i}-\mathrm{c}_{1}$

Import of cytochrome $c_{1}$ was performed in two separate reactions. In the first one $p-c_{1}$ was accumulated in the presence of EDTA and o-phenanthroline; in the second $\mathrm{i}-\mathrm{c}_{1}$ was generated by omitting NADH during import (experimental conditions as in Figure 7). Mitochondria were reisolated and resuspended in sucrose/MOPS buffer containing EDTA and o-phenanthroline. Then both reactions were combined. Half of the resulting sample was sonicated as described in Figure 2 . The other half was left on ice. Both halves were divided into aliquots corresponding to $50 \mu \mathrm{g}$ of untreated mitochondria.

(A) Five aliquots of sonicated mitochondria and five aliquots of intact mitochondria were treated with the indicated amounts of proteinase $\mathrm{K}$ (Prot. $\mathrm{K}$ ) for $30 \mathrm{~min}$ on ice. Protease action was blocked by adding PMSF, and cytochrome $c_{1}$ was immunoprecipitated (see Experimental Procedures). Precipitates were separated by electrophoresis, and fluorographs of dried gels were evaluated by densitometry. The amount of cytochrome $c_{1}$ protected against proteinase $K$ in intact mitochondria was set to 1

(B) Three aliquots of intact mitochondria were subjected to sonication and protease treatment $(15 \mu \mathrm{g} / \mathrm{ml}$, final concentration) as indicated. In one aliquot protease was added prior to sonication (Son./Prot.). In this case protease treatment was continued after sonication for $25 \mathrm{~min}$ at $0^{\circ} \mathrm{C}$. Cytochrome $c_{1}$ was immunoprecipitated, and the amounts of p- $c_{1}$ (hatched columns) and i- $c_{1}$ (open columns) were quantified. Data are expressed as percentages of total cytochrome $c_{1}$ protease-protected in intact mitochondria.

$\mathrm{M} \mathrm{NaCl}$ ). To control for the significance of this result, we incubated reticulocyte lysate containing newly synthesized (soluble) p-c $c_{1}$ with sonicated mitochondrial membranes in the presence of different concentrations of salt. Upon centrifugation, more than $90 \%$ of this $p-c_{1}$ was recovered in the pellet. The same result was obtained with membranes that had been treated with $0.1 \mathrm{M} \mathrm{Na}_{2} \mathrm{CO}_{3}$ at pH 11.5 according to Fujiki et al. (1982) (data not shown).

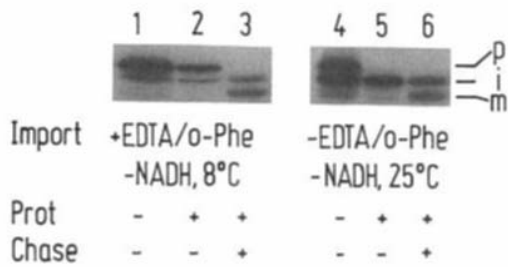

Figure 10. Processing of Imported $\mathrm{p}-\mathrm{c}_{1}$ and $\mathrm{i}-\mathrm{c}_{1}$ to $\mathrm{m}-\mathrm{c}_{1}$ p-c. was imported into mitochondria in two groups of reactions (experimental conditions as in Figure 7). The first contained EDTA and o-phenanthroline to accumulate imported p- $\mathrm{c}_{1}$ (lanes 1-3). In the second group of reactions import was performed in the absence of chelators. NADH was omitted to accumulate $i-c_{1}$ (lanes 4-6). Mitochondria were reisolated and resuspended in sucrose/MOPS buffer containing chelators (lanes 1-3) or in sucrose/MOPS buffer alone (lanes 4-6). Two reactions of each group were treated with proteinase $K$ (lanes $2,3,5$, and 6). Prior to a chase period for $30 \mathrm{~min}$ at $25^{\circ} \mathrm{C}$, reactions shown in lanes 3 and 6 received a postribosomal supernatant of untranslated reticulocyte lysate and BSA buffer to $25 \%$ and $50 \%$ of the total volume respectively, and both reactions were brought to $1 \mathrm{mM} \mathrm{NADH}$. In addition, reaction shown in lane 3 received $1 \mathrm{mM} \mathrm{MnCl}_{2}$ (final concentration). Reactions shown in lanes 1, 2, 4, and 5 remained for 30 min on ice. Then mitochondria were reisolated from all reactions and analyzed by electrophoresis and fluorography.

\section{Precursor to Cytochrome $c_{1}$ Imported into the} Matrix is on the Correct Import Pathway

Precursor was imported at low temperature into a protease-protected location in the mitochondrial matrix (Figure 10, lanes 1 and 2). Mitochondria were reisolated and resuspended in fresh import buffer allowing for the reactivation of the processing peptidase. During a subsequent chase period, $\mathrm{Mn}^{2+}, \mathrm{NADH}$, and untranslated reticulocyte lysate were added and the reaction warmed up to $25^{\circ} \mathrm{C}$ (Figure 10, lane 3). Under these conditions, most of the accumulated $p-c_{1}$ was processed to $m-c_{1}$. Thus, precursor translocated across both mitochondrial membranes is an authentic intermediate on the native assembly pathway. In addition to NADH, the presence of a factor contained in reticulocyte lysate was found to be necessary for efficient processing of $i-c_{1}$ to $m-c_{1}$. Intermediate $c_{1}$ accumulated in the absence of NADH (Figure 10 , lanes 4 and 5 ) could be processed to $m-c_{1}$ with the same efficiency as $p-c_{1}$ (Figure 10, lane 6 ). These data suggest that $p-c_{1}$ follows a route into the intermembrane space very similar to $p-b_{2}$.

\section{Discussion}

The following import and sorting pathway of cytochrome $b_{2}$ is suggested. Precursor first binds specifically to receptors on the outer surface of mitochondria (Riezmann et al., 1983). Then complete translocation across outer and inner membranes takes place at contact sites (Hartl et al., 1987a; Płanner et al., 1987a). This step is dependent on the membrane potential across the inner membrane. Under conditions where the activity of the processing peptidase is inhibited, precursor accumulates in the matrix. After the first proteolytic processing, $i-b_{2}$ is redirected back across the inner membrane. This step appears to be 
independent of the membrane potential. The second proteolytic event then occurs at the outer surface of the inner membrane, thereby generating $m-b_{2}$ soluble in the intermembrane space.

Import and sorting of cytochrome $c_{1}$ follows the same general pathway. Also, in this case precursor is first translocated across both mitochondrial membranes. Due to the property of newly synthesized $p-c_{1}$ to attach unspecifically to mitochondrial membranes, it was impossible to decide whether $p-c_{1}$ is also accumulated in the matrix as a soluble species. It is possible that imported $p-c_{1}$ interacts with the inner surface of the inner membrane either via the hydrophobic segment in the presequence or via the potential hydrophobic anchor near the carboxyl terminus of the molecule (Römisch et al., 1987). In any case, the precursor is translocated across the inner membrane since it was found protected against externally added protease in mitoplasts but was completely digested following mild mechanical disruption of mitochondria. $i-c_{1}$ is generated by the processing peptidase in the matrix and is transported back across the inner membrane. Processing at the outer surface of the inner membrane yields $m-c_{1}$, which remains anchored to the inner membrane, probably via the hydrophobic stretch of 15 amino acids near the C-terminus (Römisch et al., 1987).

Transfer of $p-b_{2}$ and $p-c_{1}$ across the inner membrane during import was not stopped by the hydrophobic stretch of about 20 amino acid residues, contained in the carboxyterminal part of the presequences (positions 53 to 73 in $b_{2}$ and positions 43 to 62 in $c_{1}$; Guiard, 1985; Römisch et al., 1987). We have recently shown for several different precursors (including cytochrome $b_{2}$ ) that transport across both mitochondrial membranes at contact sites occurs through a hydrophilic environment (possibly a proteinaceous channel) (Pfanner et al., 1987a). A potential hydrophobic stop-transfer sequence (Kaput et al., 1982; Hurt and van Loon, 1986), however, could only be effective by strong protein-lipid interaction; this does not seem to occur during transport of proteins from the cytoplasm across the mitochondrial membranes. Our experimental data rather suggest that the $\mathrm{N}$-terminal prepieces of intermediate-sized $b_{2}$ and $c_{1}$ contain the targeting information for export of the protein across the inner membrane. In both cases the intermediate-sized species were retranslocated. Removal of the prepieces of the intermediates occurs at the outer surface of the inner membrane by an as yet uncharacterized protease(s) (see also Pratje and Guiard, 1986). Membrane translocation is mechanistically independent of processing.

Precursor of the Rieske $\mathrm{Fe} / \mathrm{S}$ of the cytochrome $\mathrm{bc}_{1}$ complex (complex III) is also first translocated into the matrix of mitochondria in the course of import (Hartl et al., 1986; Hartl et al., 1987b). In this case, however, retranslocation from the matrix across the inner membrane follows a different mechanism. The precursor of the $\mathrm{Fe} / \mathrm{S}$ protein lacks a hydrophobic segment in the presequence. Processing to the mature size already takes place inside the inner membrane, i.e., targeting information for retransiocation and assembly resides in the mature part of the protein (Hartl and Neupert, unpublished data). Interestingly, a bacterial Fe/S protein that was found to be synthesized without a cleavable hydrophobic signal sequence is translocated into the periplasmic space and may thus follow a transport mechanism similar to the mitochondrial Rieske Fe/S protein (Voordouw and Brenner, 1985).

Recently it was reported that the presequence of yeast cytochrome $c_{1}$ when fused to mouse dihydrofolate reductase directed the "passenger" protein into the mitochondrial intermembrane space (van Loon et al., 1986; van Loon and Schatz, 1987; van Loon et al., 1987). As a mechanism for intramitochondrial sorting, the authors proposed that the hydrophobic segment in the carboxy-terminal part of the presequence could act as a stop-transfer sequence, preventing complete translocation of the precursor across the inner membrane. A construct lacking this part of the presequence was imported into the matrix. These experiments, however, did not exclude the possibility that transient import of the fusion protein carrying the authentic presequence of $c_{1}$ into the matrix had also occurred, since intermediates on the import pathway were not resolved. More recently, van Loon and Schatz (1987) presented data showing that the fusion between the full presequence of cytochrome $c_{1}$ and dihydrofolate reductase after import in vitro was not found in a protease-protected position in mitoplasts when the matrix peptidase was blocked by chelators. (Import of authentic $p-c_{1}$ was not tested.)

In the light of our data, these results may be explained as follows. It was not shown that the accumulated precursor of the construct was on the native assembly pathway (e.g., by releasing the block of the matrix peptidase to demonstrate processing; see Figures 8 and 10). Furthermore, it was not excluded that import into the matrix took place but the uncleaved precursor was retranslocated across the inner membrane. When we performed import of $p-b_{2}$ and $p-c_{1}$ at $20^{\circ} \mathrm{C}$ instead of at $12^{\circ} \mathrm{C}$ or $8^{\circ} \mathrm{C}$, we found significantly less protease-protected precursor in mitoplasts (the intactness of mitoplasts was not influenced by the temperature during incubation). The fraction of total $\mathrm{p}-\mathrm{b}_{2}$ imported at $12^{\circ} \mathrm{C}$ that was protease-sensitive in mitoplasts probably represented precursor that was retranslocated from the matrix across the inner membrane. It has been demonstrated that precursor proteins could be translocated across the membrane of the endoplasmic reticulum or across the bacterial plasma membrane even when unrelated sequences had been fused to the amino terminus of the signal peptide (Perara and Lingappa, 1985; Simon et al., 1987; Rottier et al., 1987; Talmadge et al., 1981; Hayashi et al., 1985). Finally, it is quite possible that the fusion protein between the presequence of cytochrome $c_{1}$ and dihydrofolate reductase behaved differently compared with the authentic precursor. In fact, the fusion protein was never cleaved to the mature form, but remained at the intermediate stage. It may well be that the hydrophobic sequences in precursors of cytochromes $b_{2}$ and $c_{1}$ act properly only in conjunction with the authentic mature protein; when placed in front of an unrelated protein they could lead to aberrant behavior of the precursor proteins in the course of sorting.

The characteristics of the retranslocation of the inter- 
mediate-sized species of cytochromes $b_{2}$ and $c_{1}$ across the inner membrane are reminiscent of those of protein transport across the plasma membrane in prokaryotes. In bacteria, proteins destined for secretion are synthesized with amino-terminal signal peptides that typically carry several positively charged residues at the amino-terminal end followed by a hydrophobic stretch of 14 to 20 residues (Duffaud et al., 1985). In fact, the intermediate prepieces of cytochromes $b_{2}$ and $c_{1}$ have a similar structure. The $\mathrm{N}$-termini of the intermediate forms of cytochromes $\mathrm{b}_{2}$ and $c_{1}$ have not yet been determined. However, comparison with a number of known cleavage sites of the matrix peptidase (Schmidt et al., 1984; Hartl et al., 1986) suggests that the intermediate forms begin 21 and 15 amino acid residues, respectively, before the hydrophobic segments (Guiard, 1985; Sadler et al., 1984; Römisch et al., 1987). The exact mechanism of transport of $i-b_{2}$ and $i-c_{1}$ across the inner membrane remains to be determined. The intermediates may assume a membrane-spanning arrangement after retranslocation, leaving the mature part exposed to the intermembrane space. The extractability of $\mathrm{i}-\mathrm{b}_{2}$ by sodium carbonate would then indicate that the membrane-associated segment is shielded by proteins (possibly of the retranslocation apparatus) from direct lipid contact.

Based on the hypothesis of the endosymbiotic origin of mitochondria, we suggest that transport of proteins from the matrix across the inner membrane follows a mechanism already developed in the prokaryotic ancestor of mitochondria. The cytochrome bc $_{1}$ complex of the photosynthetic bacterium Rhodopseudomonas sphaeroides contains a cytochrome $c_{1}$ homologous in structure, function, and topology to the mitochondrial $c_{1}$ (Gabellini et al., 1985; Hauska et al., 1983). It is made in the cytoplasm of the bacterium with a 21 amino acid presequence that is similar to the prepiece of the intermediate form of mitochondrial cytochrome $c_{1}$ (Gabellini and Sebald, 1986; Sadler et al., 1984; Römisch et al., 1987). In the bacterium the precursor is translocated to the periplasmic side of the photosynthetic membrane and processed to the mature subunit. We propose that this assembly pathway has been conserved during evolution and is still followed in mitochondria with regard to export from the matrix (corresponding to the bacterial cytoplasm) across the inner membrane (corresponding to the bacterial plasma membrane). The same principle seems to be followed in intrachloroplast sorting for transport from the stroma across the thylakoid membrane (Smeekens et al., 1986). Cytochrome $f$, the equivalent of cytochrome $c_{1}$ in the thylakoid cytochrome $b_{6} f$ complex (Hauska et al., 1983), is made in the chloroplast stroma with an amino-terminal presequence of 35 amino acids that again exhibits typical features of bacterial signal sequences and similarity to the intermediate prepiece of mitochondrial $c_{1}$ (Alt and Herrmann, 1984). We propose that mitochondrial precursors with a bipartite presequence destined for the intermembrane space are first imported into the matrix. After processing by the matrix peptidase, the intermediate enters the ancestral assembly pathway.

\section{Experimental Procedures}

\section{Isolation of Mitochondrie}

Wild-type Saccharomyces cerevisiae (D 273-10B) was grown on 2\% lactate and mitochondria were isolated essentially according to Daum et al. (1982). For preparation of spheroplasts, cells were incubated with Zymolyase-20T (Seikagaku Kogyo Co.) at $5 \mathrm{mg}$ per $\mathrm{g}$ wet weight of cells for $30 \mathrm{~min}$ at $30^{\circ} \mathrm{C}$. Homogenization of spheroplasts was carried out by 10 strokes in a Dounce homogenizer in a medium containing $0.6 \mathrm{M}$ mannitol, $0.5 \%$ BSA (Sigma), $1 \mathrm{mM}$ PMSF, and $10 \mathrm{mM}$ Tris (pH 7.4) Mitochondria were finally resuspended in SEM buffer $(250 \mathrm{mM}$ sucrose, $1 \mathrm{mM}$ EDTA, and $10 \mathrm{mM}$ MOPS/KOH [pH 7.2]) at a protein concentration of $5 \mathrm{mg} / \mathrm{ml}$. Growth of $\mathrm{N}$. crassa (wild type 74A) and isolation of mitochondria were performed as previously described (Schleyer et al., 1982; Schwaiger et al., 1987).

\section{Import of Precursor Proteins In Vitro}

$p-b_{2}, p-c_{1}$, and $p-F e / S$ were synthesized by coupled transcriptiontranslation (Stueber et al., 1984; Krieg and Melton, 1984; Pelham and Jackson, 1976). For cytochrome $b_{2}$, the genomic clone described previously was used (Guiard, 1985). For cytochrome $c_{1}$ and the $\mathrm{Fe} / \mathrm{S}$ protein, a full-length cDNA was isolated from an N. crassa library constructed according to Gubler and Hoffmann (1983) and cloned into pGEM-3 (Hartl et al., 1987a; Rassow and Neupert, unpublished data) Postribosomal supernatants of reticulocyte lysates were prepared and supplemented as published (Zimmermann and Neupert, 1980). Reticulocyte lysates lacking labeled mitochondrial precursor proteins were prepared according to Pfanner and Neupert (1985). Import mixtures usually contained $10 \%-20 \%$ reticulocyte lysate in BSA buffer ( $3 \%$ BSA, $220 \mathrm{mM}$ sucrose, $80 \mathrm{mM} \mathrm{KCl}$, and $10 \mathrm{mM}$ MOPS/KOH [pH 7.2) and $2 \mathrm{mM} \mathrm{NADH}$. In addition, $1.5 \mathrm{mM}$ ATP was included for import of cytochrome $\mathrm{b}_{2}$. Mitochondria were added to a concentration of 0.5 $\mathrm{mg}$ per $\mathrm{ml}$ of import reaction. Inhibition of the matrix-localized processing peptidase, inhibition of the mitochondrial membrane potential, and protease treatment of mitochondria after import were carried out as recently described (Schmidt et al., 1984; Hartl et al., 1986). Control reactions received the same volume of inhibitor-free solutions.

\section{Subfractionation of Mitochondria}

Alkaline treatment of mitochondria (Fujiki et al., 1982) and analysis of solubility of imported cytochrome $b_{2}$ (Hartl et al., 1986) were carried out as published. Digitonin fractionation was carried out in the presence of $100 \mathrm{mM} \mathrm{KCl}$ (cytochrome $c_{1}$ ) or $200 \mathrm{mM} \mathrm{KCl}$ (cytochrome $b_{2}$ ) as described previously (Hartl et al., 1986). Osmotic shock treatment of mitochondria followed the method of Daum et al. (1982). Mitochondria were reisolated from the import reactions by centrifugation and resuspended at a concentration of $1 \mathrm{mg} / \mathrm{ml}$ in $10 \mathrm{mM}$ MOPS ( $\mathrm{pH} 7.2$ ) containing $0-0.6 \mathrm{M}$ sorbitol. Incubation was for $15 \mathrm{~min}$ at $0^{\circ} \mathrm{C}$. Then the reactions were brought to $0.6 \mathrm{M}$ sorbitol by addition of $1.2 \mathrm{M}$ sorbitol, adjusting the protein concentration to $0.5 \mathrm{mg} / \mathrm{ml}$. Aliquots corresponding to $25 \mu \mathrm{g}$ of untreated mitochondria were treated with proteinase $\mathrm{K}$ (15 $\mu \mathrm{g} / \mathrm{ml}$, final concentration) for $30 \mathrm{~min}$ on ice or separated into pellets and supernatants by centrifugation for $20 \mathrm{~min}$ at $48,000 \times \mathrm{g}$.

\section{Miscellaneous}

The following procedures were performed according to published methods: enzyme assays of cytochrome $b_{2}$ (Appleby and Morton, 1959), adenylate kinase, and fumarase (Schmidt et al., 1984); immunoprecipitation of cytochrome $b_{2}$, cytochrome $c_{1}$, and the $\mathrm{Fe} / \mathrm{S}$ protein (Schleyer et al., 1982; Hartl et al., 1986); protein determination (Bradford, 1976); electrophoresis on 10\% (cytochrome $b_{2}$ ) and $17 \%$ (cytochrome $c_{1}$ and $\mathrm{Fe} / \mathrm{S}$ protein) polyacrylamide gels (Laemmli, 1970); fluorography and quantitation of fluorographs by densitometry (Hartl et al., 1986).

\section{Acknowledgments}

The authors appreciate the expert technical assistance of Sigrun Meier and Inge Kohl. We thank Dr. Maximilian Tropschug and Joachim Rassow for help with the isolation of cDNA clones, Dr. H. Weiss for an antiserum against cytochrome $c_{1}$, and Dr. M. A. Harmey for critically 
reading the manuscript. This work was supported by the Deutsche Forschungsgemeinschaft (Grant SFB 184, B2).

The costs of publication of this article were defrayed in part by the payment of page charges. This article must therefore be hereby marked "advertisement" in accordance with 18 Section U.S.C. 1734 solely to indicate this fact.

Received September 1, 1987.

\section{References}

Alt, J., and Herrmann, R. G. (1984). Nucleotide sequence of the gene for pre-apocytochrome $f$ in the spinach plastid chromosome. Curr. Genet. 8, 551-557.

Appleby, C. A., and Morton, R. K. (1959). Lactic dehydrogenase and cytochrome $b_{2}$ of baker's yeast. Purification and crystallization. Biochem. J. 71, 492-499.

Böhni, P., Gasser, S., Leaver, C., and Schatz, G. (1980). A matrixlocalized mitochondrial protease processing cytoplasmically-made precursors to mitochondrial proteins. In The Organization and Expression of the Mitochondrial Genome, A. M. Kroon and C. Saccone, eds. (Amsterdam: Elsevier/North-Holland), pp. 432-433.

Bradford, M. M. (1976). A rapid and sensitive method for the quantitation of microgram quantities of protein utilizing the principle of proteindye binding. Anal. Biochem. 72, 248-254.

Chen, W.-J., and Douglas, M. G. (1987). Phosphodiester bond cleavage outside mitochondria is required for the completion of protein import into the mitochondrial matrix. Cell 49, 651-658.

Conboy, J. G., Fenton, W. A., and Rosenberg, L. E. (1982). Processing of pre-ornithine transcarbamylase requires a zinc-dependent protease localized to the mitochondrial matrix. Biochem. Biophys. Res. Commun. $105,1-7$.

Daum, G., Gasser, S. M., and Schatz, G. (1982). Import of proteins into mitochondria. Energy-dependent, two-step processing of the intermembrane space enzyme cytochrome $b_{2}$ by isolated yeast mitochondria. J. Biol. Chem. 257, 13075-13080.

Dowhan, W., Bibus, C. R., and Schatz, G. (1985). The cytoplasmicallymade subunit IV is necessary for assembly of cytochrome $c$ oxidase in yeast. EMBO J. 4, 179-184.

Duffaud, G. D., Lehnhardt, S. K., March, P. E., and Inouye, M. (1985). Structure and function of the signal peptide. In Current Topics in Membranes and Transport, Vol. 24, F. Bonner, ed.; P. A. Knauf and J. S. Cook, guest eds. (New York: Academic Press), pp. 65-104.

Eilers, M., Oppliger, W., and Schatz, G. (1987). Both ATP and an energized inner membrane are required to import a purified precursor protein into mitochondria. EMBO J. 6, 1073-1077.

Fujiki, Y., Hubbard, A. L., Fowler, S., and Lazarow, P. B. (1982). Isolation of intracellular membranes by means of sodium carbonate treatment application to endoplasmic reticulum. J. Cell Biol. 93, 97-102.

Gabellini, N., and Sebald, W. (1986). Nucleotide sequence and transcription of the fbc operon from Rhodopseudomonas sphaeroides. Evaluation of the deduced amino acid sequences of the FeS protein, cytochrome $b$ and cytochrome $c_{1}$. Eur. J. Biochem. 154, 569-579.

Gabellini, N., Harnisch, U., McCarthy, J. E. G., Hauska, G., and Sebald, $W$. (1985). Cloning and expression of the fbc operon encoding the FeS protein, cytochrome $b$ and cytochrome $c_{1}$ from Rhodopseudomonas sphaeroides $\mathrm{b} / \mathrm{c}_{1}$ complex. EMBO J. 4, 549-553.

Gasser, S. M., Daum, G., and Schatz, G. (1982a). Import of proteins into mitochondria. Energy-dependent uptake of precursors by isolated mitochondria. J. Biol. Chem. 257, 13034-13041.

Gasser, S. M., Ohashi, A., Daum, G., Boehni, P. C., Gibson, J., Reid, G. A., Yonetani, T., and Schatz, G. (1982b). Imported mitochondrial proteins cytochrome $b_{2}$ and cytochrome $c_{1}$ are processed in two steps. Proc. Natl. Acad. Sci. USA 79, 267-271.

Gubler, U., and Hoffmann, B. J. (1983). A simple and very efficient method for generation of cDNA libraries. Gene 25, 263-269.

Guiard, B. (1985). Structure, expression and regulation of a nuclear gene encoding a mitochondrial protein: the yeast $L(+)$-lactate cytochrome $c$ oxidoreductase (cytochrome $b_{2}$ ). EMBO J. 4, 3265-3272.
Hallermayer, G., Zimmermann, R., and Neupert, W. (1977). Kinetic studies on the transport of cytoplasmically synthesized proteins into the mitochondria in intact cells of Neurospora crassa. Eur. J. Biochem. 81, 523-532.

Harmey, M. A., and Neupert, W. (1985). Intracellular transfer of mitochondrial membrane proteins. In The Enzymes of Biological Membranes, Vol. 4, A. Martonosi, ed. (New York: Plenum Publishing Corp.), pp. 431-464.

Hartl, F.-U., Schmidt, B., Wachter, E., Weiss, H., and Neupert, W. (1986). Transport into mitochondria and intramitochondrial sorting of the $\mathrm{Fe} / \mathrm{S}$ protein of ubiquinol-cytochrome c reductase. Cell $47,939-$ 951

Hartl, F.-U., Ostermann, J., Pfanner, N., Tropschug, M., Guiard, B., and Neupert, $W$. (1987a). Import of cytochromes $b_{2}$ and $c_{1}$ into mitochondria requires both membrane potential and nucleoside triphosphates. In Cytochrome Systems: Molecular Biology and Energetics, S. Papa et al., eds. (New York: Plenum Publishing $\mathrm{Co}_{\mathrm{o}}$ ), in press.

Hartl, F.U., Pfanner, N., and Neupert, W. (1987b). Translocation intermediates on the import pathway of proteins into mitochondria. Biochem. Soc. Trans. 15, 95-97.

Hauska, G., Hurt, E., and Lockau, W. (1983). Comparative aspects of quinol-cytochrome c/plastocyanin oxidoreductases. Biochim. Biophys. Acta 726, 97-133.

Hay, R., Böhni, P., and Gasser, S. (1984). How mitochondria import proteins. Biochim. Biophys. Acta 779, 65-87.

Hayashi, S., Chang, S.-Y., Chang, S., Giam, C.-Z., and Wu, H. C. (1985). Modification and processing of internal signal sequences of prolipoprotein in Escherichia coli and in Bacillus subtilis. J. Biol. Chem. 260, 5753-5759.

Hurwich, A. L., Kaluusek, F., Mellman, I., and Rusenberg, L. E. (1985). A leader peptide is sufficient to direct mitochondrial import of a chimeric protein. EMBO J. 4, 1129-1135.

Hurt, E. C., and van Loon, A. P. G. M. (1986). How proteins find mitochondria and intramitochondrial compartments. Trends Biochem. Sci. 11, 204-207.

Hurt, E. C., Pesold-Hurt, B., and Schatz, G. (1984a). The cleavable prepiece of an imported mitochondrial protein is sufficient to direct cytosolic dihydrofolate reductase into the mitochondrial matrix. FEBS Lett. 178, 306-310

Hurt, E. C., Pesold-Hurt, B., and Schatz, G. (1984b). The aminoterminal region of an imported mitochondrial precursor polypeptide can direct cytoplasmic dihydrofolate reductase into the mitochondrial matrlx. EMBO J. 3, 3149-3156.

Kaput, J., Goltz, S., and Blobel, G. (1982). Nucleotide sequence of the yeast nuclear gene for cytochrome $c$ peroxidase precursor. Functional implications of the pre-sequence for protein transport into mitochondria. J. Biol. Chem. 257, 15054-15058.

Kolanski, D. M., Conboy, J. G., Fenon, W. A., and Rosenberg, L. (1982). Energy-dependent translocation of the precursor of ornithine transcarbamylase by isolated rat liver mitochondria. J. Biol. Chem. 257, 84678471.

Krieg, P. A., and Melton, D. A. (1984). Functional messenger RNAs are produced by SP6 in vitro transcription of cloned cDNAs. Nucl. Acids Res. 12, 7057-7070.

Laemmli, V. K. (1970). Cleavage of structural proteins during the assembly of the head of bacteriophage T4. Nature 227, 680-685.

Lewin, A. S., and Norman, D. K. (1983). Assembly of $F_{1}$ ATPase in isolated mitochondria. J. Biol. Chem. 258, 6750-6755.

Li, Y., Leonard, W., and Weiss, H. (1981). Membrane-bound and watersoluble cytochrome $c_{1}$ from Neurospora mitochondria. Eur. J. Biochem. 116, 199-205

McAda, P., and Douglas, M. G. (1982). A neutral metallo endoprotease involved in the processing of an $F_{1}$ ATPase subunit precursor in mitochondria. J. Biol. Chem. 257, 3177-3182.

Miura, S., Mori, M., Amaya, Y., and Tatibana, M. (1982). A mitochondrial protease that cleaves the precursor of ornithine carbamoyl transterase. Eur. J. Biochem. 122, 641-647.

Ohashi, A., Gibson, J., Gregor, I., and Schatz, G. (1982). Import of pro- 
teins into mitochondria. The precursor of cytochrome $c_{1}$ is processed in two steps, one of them heme-dependent. J. Biol. Chem. 257 , $13042-13047$.

Pelham, H. R. B., and Jackson, R. J. (1976). An efficient mRNAdependent translation system from reticulocyte lysates. Eur. J. Biochem. 67, 247-256

Perara, E., and Lingappa, V. R. (1985). A former amino terminal signa sequence engineered to an internal location directs translocation of both flanking protein domains. J. Cell Biol. 101, 2292-2301.

Pfanner, N., and Neupert, W. (1985). Transport of proteins into mitochondria: a potassium diffusion potential is able to drive the import of ADP/ATP carrier. EMBO J. 4, 2819-2825

Pfanner, N., and Neupert, W. (1986). Transport of $F_{1}$ ATPase subunit $\beta$ into mitochondria depends on both a membrane potential and nucleoside triphosphates. FEBS Lett. 209, 152-156.

Pfanner, N., and Neupert, W. (1987). Biogenesis of mitochondria energy transducing complexes. In Current Topics in Bioenergetics, Vol 15, C. P. Lee, ed. (New York: Academic Press), pp. 177-219.

Pfanner, N., Hartl, F.-U., Guiard, B., and Neupert, W. (1987a). Mitochondrial precursor proteins are imported through a hydrophilic membrane environment. Eur. J. Biochem., in press.

Pfanner, N., Hoeben, P., Tropschug, M., and Neupert, W. (1987b). The carboxy-terminal two thirds of the ADPIATP carrier polypeptide contains sufficient information to direct translocation into mitochondria. $J$. Biol. Chem., in press.

Pfanner, N., Tropschug, M., and Neupert, W. (1987c). Mitochondrial protein import: nucleoside triphosphates are involved in conferring import-competence to precursors. Cell, 49, 815-823.

Pratje, E., and Guiard, B. (1986). One nuclear gene controls the removal of transient pre-sequences from two yeast proteins: one encoded by the nuclear the other by the mitochondrial genome. EMBO J. 5, 1313-1317.

Riezmann, H., Hay, R., Witte, C., Nelson, N., and Schatz, G. (1983) Yeast mitochondrial outer membrane specifically binds cytoplasmically-synthesized precursors of mitochondrial proteins. EMBO J. 2 , 1113-1118.

Römisch. J., Tropschug, M., Sebald, W., and Weiss, H. (1987). The primary structure of cytochrome $c_{1}$ from Neurospora crassa. Eur. J. Biochem. 164, 111-115.

Rottier, P. J. M., Florkiewicz, R. Z., Shaw, A. S., and Rose, J. K. (1987). An internalized amino-terminal signal sequence retains full activity in vivo but not in vitro. J. Biol. Chem. 262, 8889-8895.

Sadler, J., Suda, K., Schatz, G., Kaudewitz, F., and Haid, A. (1984). Sequencing of the nuclear gene for the yeast cytochrome $c_{1}$ precursor reveals an unusually complex amino-terminal presequence. EMBO J. 9, 2137-2143.

Schatz, G. (1979). How mitochondria import proteins from the cytoplasm. FEBS Lett. 103, 203-211.

Schleyer, M., and Neupert, W. (1985). Transport of proteins into mitochondria: translocation intermediates spanning contact sites between outer and inner membranes. Cell 43, 339-350.

Schleyer, M., Schmidt, B., and Neupert, W. (1982). Requirement of a membrane potential for the posttranslational transfer of proteins into mitochondria. Eur. J. Biochem. 125, 109-116.

Schmidt, B., Hennig, B., Zimmermann, R., and Neupert, W. (1983). Biosynthetic pathway of mitochondrial ATPase subunit 9 in Neurospora crassa. J. Cell Biol. 96, 248-255.

Schmidt, B., Wachter, E., Sebald, W., and Neupert, W. (1984). Processing peptidase of Neurospora mitochondria. Two step cleavage of imported ATPase subunit 9. Eur. J. Biochem. 144, 581-588.

Schwaiger, M., Herzog, V., and Neupert, W. (1987). Characterization of translocation contact sites involved in the import of mitochondrial proteins. J. Cell Biol. 105, 235-246.

Simon, K., Perara, E., and Lingappa, V. R. (1987). Translocation of globin fusion proteins across the endoplasmic reticulum membrane in Xenopus laevis oocytes. J. Cell Biol. 104, 1165-1172.

Smeekens, S., Bauerle, C., Hageman, J., Keegstra, K., and Weisbeek,
P. (1986). The role of the transit peptide in the routing of precursors toward different chioroplast compartments. Cell 46, 365-375.

Stueber, D., Ibrahimi, I., Cutler, D., Dobberstein, B., and Bujard, H. (1984). A novel in vitro transcription-translation system: accurate and efficient synthesis of single proteins from cloned DNA sequences. EMBO J. 3, 3143-3148.

Talmadge, K., Broslus, J., and Gilbert, W. (1981). An "internal" signa sequence directs secretion and processing of proinsulin in bacteria. Nature 294, 176-178

Teintze, M., Slaughter, M., Weiss, H., and Neupert, W. (1982). Biogenesis of mitochondrial ubiquinol:cytochrome $c$ reductase (cytochrome $\mathrm{bc}_{1}$ complex). J. Biol. Chem. 257, 10364-10371.

van Loon, A. P. G. M., and Schatz, G. (1987). Transport of proteins to the mitochondrial intermembrane space: the "sorting" domain of the cytochrome $c_{1}$ presequence is a stop-transier sequence specific for the mitochondrial inner membrane. EMBO J. 6, 2441-2448.

van Loon, A. P. G. M., Brändli, A., and Schatz, G. (1986). The presequences of two imported mitochondrial proteins contain imformation for intracellular and intramitochondrial sorting. Cell 44, 801-812.

van Loon, A. P. G. M., Brändli, A. W., Pesold-Hurt, B., Blank, D., and Schatz, G. (1987). Transport of proteins to the mitochondrial intermembrane space: the "matrix-targeting" and the "sorting" domains in the cytochrome $c_{1}$ presequence. EMBO J. 6, 2433-2439.

Voordouw, G., and Brenner, S. (1985). Nucleotide sequence of the gene encoding the hydrogenase from Desulfovibrio vulgaris (Hildenborough). Eur. J. Biochem. 148, 515-520.

Zimmermann, R., and Neupert, W. (1980). Transport of proteins into mitochondria: posttranslational transfer of ADPIATP carrier into mitochondria. Eur. J. Biochem. 109, 217-229.

Zwizinski, C., Schleyer, M., and Neupert, W. (1984). Proteinaceous receptors for the import of mitochondrial precursor proteins. J. Biol. Chem. 259, 7850-7856. 